\title{
The future of the Basic Education Assistance Module, a poverty alleviation strategy in Zimbabwe
}

\author{
Florence Mutasa \\ Department of Politics and Public Management, Midlands State University \\ P. Bag 9055, Gweru, Zimbabwe \\ Emil:missfmutasa@gmail.com
}

Doi:10.5296/ jpag.v5i3.8331 URL: http://dx.doi.org/10.5296/ jpag.v5i3.8331

\begin{abstract}
The aim of this article is to give an insight into the future of the Basic Education Assistance Module (BEAM) by highlighting the problems faced in its implementation and mapping the way forward for the programme to be a success. Through a review of scholarly literature, an overview of the concept of beneficiary participation, which is the fundamental aspect of BEAM is given, and through interviews and focus group discussions an assessment of the effectiveness of the programme is made. This article has shown that the implementation of BEAM is plagued with a plethora of problems. For BEAM to be effective, all the stakeholders, that is, the school authorities, teachers, parents and guardians, community members as well as the government have a significant role to play.
\end{abstract}

Keywords: Policy, implementation, participation, community, beneficiary. 


\section{Introduction}

The primary objective of BEAM as a poverty alleviation strategy is to reduce the number of children dropping out and reach out to children who have never been to school due to economic hardships. The strength of BEAM lies in that it is a community based beneficiary targeting programme which allows community participation in selection of the neediest children. This is a departure from the old government education assistance approach where targeted beneficiaries had to individually approach the Ministry of Public Service, Labour and Social Welfare (MPSLSW) to get assistance. Literature on poverty advocates bottom-up participatory approaches to development as a lasting solution to poverty alleviation. However, prior research indicates that BEAM has not been as effective as expected. This article aims to explore the pitfalls of BEAM and proffer recommendations for the enhancement of the implementation of the programme.

\subsection{Background of the study}

When the Zimbabwe Government adopted The Framework of Economic Reform programme in 1991, there were considerable transitional hardships inflicted on the vulnerable groups namely the disabled, women, children and the aged. Again the removal of subsidies on basic social services like education, health and food resulted in severe hardships for the poorer members of society. Cost recovery in the education sector for example, had disastrous effects on the children from poor families as parents were now required to pay fees, even at primary school level in urban areas (Mwanza, 1999). Generally poor parents were withdrawing children from school because of lack of funds more so as they graduated from primary to secondary school. (MPSLSW), 1997).

Learning from the experiences of other countries implementing similar programmes, the government of Zimbabwe had anticipated transitory economic difficulties, such as high levels of inflation and unemployment. Based on this assumption, the government in November 1991 introduced the SDA programme to cushion the poor from the social effects of the ESAP. This resulted in the establishment of the SDF in the MPSLSW to coordinate programmes targeting the most vulnerable groups. The vulnerable groups are namely, the disabled, women, children and the aged. The SDF had two components namely; direct transfers to support health and school fees payments for poor households, and, employment and training programmes to retrain retrenched workers.

However, in 1994 under the newly initiated PAAP which was broader in focus, Government initiated a review of the SDF due to several problems which were being faced. The system had created arrears which became burdens for the fiscus and school authorities. The Department of Social Welfare also used means testing whereby potential beneficiaries presented themselves to the Department of Social Welfare in order to access the assistance that was provided, but this had its bottlenecks. For those means tested, several problems arose. Firstly, accessing the Department of Social Welfare by the majority of the target beneficiaries was difficulty. Secondly, costs of administering the system were high. Thirdly, targeting of people who deserved the assistance was poor, and finally, there was poor geographic coverage which resulted in few people benefiting. 
It is against his background that the Government developed the BEAM. BEAM is mainly focused on improving efficiency and transparency and ensuring speedy delivery in Government education assistance to vulnerable children. Of particular importance is also the role of communities in the targeting and selection procedures where communities are responsible for targeting beneficiaries through Community Selection Committees (CSC) that are established by the communities themselves.

\section{Literature Review and Theoretical Framework}

Sabbatier (1993) conceptualized policy implementation from the perspective of the top-down and the bottom-up approaches. However, since the 1970s there has been a fundamental shift from "dependency" and interventionist" theories in search for systemic alternatives; a result of development agencies realizing that the theories of development followed since the 1960s had not been successful. "Participation" has now become the hallmark of sustainable development, which a general shift form prescriptive "top-down" to participatory "bottom-up" approaches to development. The key word in the new vision is participation by all beneficiaries of development programmes: "putting people at the centre" (UNDP 1998).

A wide variety of interpretation is associated with the concept of popular participation. Lisk (19 85), after studying a number of developing countries observed that the interpretation of popular participation in a practical content varies considerably from one country setting to another, and may even vary between different regions within the same national entity. Broadly speaking it may range from the token involvement of people, indirectly in the formal decision making process to autonomous decision making by popular organizations at the local level. It can include co-operation between decision makers and those affected by their actions, without any formal surrender of power to participants, although these may be allowed to modify decisions in order to retain their cooperation. In another form, participation can concede to participants a share of formal power varying from the right to impose temporary or permanent vetoes, to rights to joint or sole decision making. Furthermore, effective communication can be obtained by negotiation between power-holders and representation groups within society. Lisk therefore suggests that because of these differences in interpretations and practices, the concept could, perhaps best be examined in a location - specific context in relation to existing political and socio-economic structures as well as cultural characteristics, all of which combine to determine the nature and scope of participation as an agent of development.

However, a United Nations publication (UNECA 1975) argues that there are basically three ways of viewing popular participation in development, namely, "mass sharing of the benefits of development; mass contribution to the development; and mass decision making in development." Makumbe (1996) notes that popular participation is therefore being viewed as both a goal of development which requires that national resources and opportunities be equitably distributed, and as a way of facilitating and energizing development efforts by means of popular involvement in developmental decision making. 
Makumbe (1996) and Lisk (1985) view beneficiary participation as only being meaningful for the masses if there are effectively involved at the various levels of the development process. For example, popular participation is considered severely limited when the masses are being merely asked to choose between alternatives initially selected by bureaucrats. The limitation of participation becomes more evident under circumstances when none of the alternatives proposed by bureaucrats meets the expectations of the masses, or fail to address what the masses may feel are their felt needs.

The UN publication (UNECA 1975) further argues that mass participation in decision making for development constitutes a critical element which distinguishes "passive" form "active" participation. Accordingly, a more comprehensive view of decision making process involves three stages: defining the situation requiring a decision; choosing the preferred alternative and evaluating the consequences of the action taken. According to the UN (1975), of these three stages, the first may well be the most important, since the way in which a problem situation is defined not only determines and possible alternative solutions but usually tends to restrict the number of relevant choices. If the people are not involved at the first stage, their participation may be limited to merely ratifying what has been determined for them.

Makumbe (1996) also notes that equally crucial to the development process is the people's participation in the evaluation process. This will enable the people to identify the constraints or problems associated or brought about by their previous decisions and may significantly influence their decisions.

Powell (1988) also argues that active participation in development requires that the community or the beneficiaries are fully involved in the whole process, from design to implementation of the programme. The community tends to be actively involved in those programmes that they have contributed to at each and every stage - design, planning, implementation and evaluation. Passive participating in when the community is expected to simply join in at the implantation stage. BEAM confirms Powell's assertion. For BEAM, only the project implementation is a responsibility of the community. The Community Selection Committee (CSC) is the implementing agent that, on behalf of the communities carries out selection of the beneficiaries. The District Education Officers form the link between CSCs, the local authorities and the Project Management Unit at the Ministry of Public Service, Labour and Social Welfare (MPSLSW).

Thus active participation goes beyond mere choice - making from among predetermined alternatives, while passive participation largely pertains to such choice-making and even manipulation of the masses by those who will have made the critical decisions in the first place.

Another aspect of participatory development is the concept of "direct" and "indirect" participation. The two terms are closely linked to the terms active and passive participation discussed above. The UN publication mentioned above argues that direct participation in decision-making for development involves physical interaction between those persons in whom society has vested the authority to make decisions and the people affected by those 
decisions. However, Makumbe (1996) argues that under normal circumstances, this form of participation is quite feasible at the local level but quite difficult if not impossible to achieve at higher levels. There can be physical interaction without the opportunity for the people or their representatives to make meaningful informed decisions. This is particularly so in most of Africa's rural communities where the bureaucrat is often "king" (Makumbe 1996).

However, despite the wide variety of interpretations associated with the concept, for the purpose of this study popular participation in development projects should be broadly understood as the active involvement of people in the making and implementation of decisions at all levels and forms of political and socio-economic activities. More specifically, in the context of planning poverty alleviation programmes like BEAM, participation relates to the involvement of the broad masses of the people in the choice, execution and evaluation of the programme. BEAM is paradigm shift where there is a change from dealing with one child and family at a time to collaborative action involving service providers, communities and recipients themselves.

It is within the framework of the participatory bottom-up approach that the analysis of the effectiveness of BEAM as a poverty alleviation strategy is made.

\section{Analysis of results}

\subsection{Problems in the implementation of BEAM and the way forward}

Indications of the study were that the BEAM programme's prospects were not bright. Respondents pointed out quite a number of problems they faced with the BEAM programme. School heads for instance, noted among other problems the inadequacy and erratic disbursement of funds which left them in a dilemma as to how many recipients were to benefit each year. To ensure that BEAM as a participatory approach towards poverty alleviation plays an effective role in reducing the number of school dropouts, the following noted problems need addressing:

\subsubsection{Inadequacy of funds}

The respondent school heads, CSC members, parents/guardians as well as the beneficiaries perceived BEAM funds as inadequate. The grant per student was inadequate and fell short of expectations in so far as alleviating the plight of poor households was concerned. The inadequacy of BEAM lay in that after the CSCs' ranking of potential beneficiaries according to levels of vulnerability, some deserving children were left out when the allocated funds were exhausted. Thus deserving children were not assisted in their entirety.

BEAM funds also catered for tuition, levy and examination fees only. No provision was made for other essentials like books, uniforms and school projects approved by the SDAs/Cs which were more expensive. As a result, students who failed to raise funds for school projects were sent away by the SDAs/Cs who were running schools, in an effort to encourage them to pay. Eventually the poor parents and guardians would have to find means and ways of raising the required amounts to supplement the BEAM allocations. Thus the poor could engage in perverse coping mechanisms against poverty like prostitution or other extremes like selling 
everything they had and become poorer, in order to send their children to school.

The inadequacy of BEAM also lay in its lack of a supplementary budget. Thus, eventual school fees hikes during the course of the year were not catered for, leaving the selected beneficiaries with balance of payments to be met by their parents and guardians. Children who were orphaned during the course of the year were also not covered since BEAM's eligible beneficiaries were only selected at the beginning of the year.

To ensure that BEAM caters for as many vulnerable children as possible annually, the budgetary allocation increments should be consistent with the increases in levels of schools fees for instance, in 2006 where fees rose by over 1000\%. BEAM should also cover eventual school fees increases during the course of the year. This can be achieved through a supplementary budget which is also inflation sensitive. The supplementary budget would meet any initial allocation budget deficit. The additional budget would also ensure that selection of beneficiaries becomes an ongoing exercise rather than an event, to cater for children who would be orphaned during the course of the year. The supplementary budget would also facilitate the transition of pupils from primary to secondary school through the provision of the requisite deposits to secure form one places. Some pupils are failing to start secondary school due to lack of funds to secure places resulting in a situation where BEAM is assisting a more substantial number of primary school pupils than secondary ones.

BEAM should also cover other essentials like books and uniforms as some of the poor parents and guardians cannot afford such items. Alternatively, where the parents are able bodied but not gainfully employed, they should be financially empowered to start self-help projects so that they put more effort towards the education of their children rather than relying on government. BEAM would focus on the most vulnerable children for instance, child headed families.

A holistic approach by government in the assessment of poverty alleviation programmes is also essential. Since government is aware of the existence of other private players' education assistance programmes in addition to BEAM, there is therefore, need for an evaluation of the extent of the other players' involvement annually in order to determine the extent to which BEAM should assist, rather than consideration of available resources as is currently the practice.

\subsubsection{Erratic disbursement of funds}

The respondent schools indicated that the disbursement of BEAM funds has been erratic over the years. The responsible ministries involved in the disbursement of funds that is, the Ministry of Finance and the MPSLSW should cut on bureaucratic red tape to ensure timeous disbursement of funds. CSC members also need thorough training by the Programme Monitoring Unit (PMU) to avoid errors in completion of forms which delay payments. Funds should be disbursed during the second week of January at the latest to avoid incidents of pupils being sent away as some schools' policy is pay first and attend later. Issues of staffing at the MPU should be treated as a matter of urgency and the installation of up to date computers is also a prerequisite. 


\subsubsection{Lack of transparency in beneficiary selection}

Indications were that transparency and accountability in the BEAM beneficiaries' selection process were being compromised resulting in undeserving children benefitting from the programme. For instance corruption was marring the target beneficiary selection process. The MPSLW should advise communities to come up with a well documented social community register of vulnerable children which is updated regularly so that identification of beneficiaries becomes easier, rather than identifying them at the beginning of every year. This will only not serve BEAM purposes but all other social welfare programmes for instances, for food, health and clothing. The register also enhances transparency in the selection process. Besides, once a child has been admitted in the scheme, there would be no reason for resubmitting forms annually as is the practice. A verification process of checking who is still present or transferred would suffice to avoid inconveniences caused by failure to re-apply annually. This also reduces the work overload for schools.

Class teachers should also be involved in identifying the neediest cases where the children are already in school since they are in day to day contact with the pupils and are also the custodians of the children's social records. The teachers should also be allowed to fill in application forms for deserving pupils where guardians are not cooperative for instance, where they fail to turn up on time, for deadlines to be met. The teachers should also play a larger role for transparency purposes as communities have turned out to have corrupt tendencies.

Secondary schools should deal with their own BEAM beneficiaries to reduce the workload of primary schools, which currently is the responsibility of the primary school heads who cater for districts under them. This will also ensure an appreciation of the operations of BEAM by the secondary school heads as some of them are sending away beneficiaries when funds are disbursed late.

\subsubsection{Limited access to information on BEAM by beneficiaries}

Respondents felt that potential beneficiaries were failing to access information on BEAM on time or may not access it at all. It was also noted that due to inhibitive costs of correspondence through writing, information dissemination on BEAM and the selection of beneficiaries to the community is generally through school children. Most parents and guardians also fail to attend meetings. Therefore, timeous information dissemination should be through other media, both print and electronic (newspapers, televisions, radios and social media) in all major languages to avoid incidents of potential beneficiaries failing to access information. Information dissemination in this manner also enables more individuals and organizations in the community to be involved in the selection process, thus improving on transparency.

\subsubsection{Inadequate community participation in the BEAM Programme}

Indications were that some members of the community were reluctant to participate in the BEAM target beneficiary process. Community members also failed to stand firm as witnesses where incidents of corruption were cited for fear of witchcraft. This created a conducive 
environment for corrupt behaviour giving room for undeserving children to be included in the programme. It can be noted that the aspect of community participation in welfare programmes is relatively new in Zimbabwe, hence there is need for intensive education of communities by the Department of Social Welfare to instill a sense of social welfare and an awareness of the need for good social relations at community level, for the success of welfare programmes. The community has abundant knowledge which if used positively has the potential to support welfare programmes like BEAM. Thus, participation of an informed community can therefore, take place at all levels of development projects in a meaningful and effective way, for instance community knowledge could have been employed by the Department of Social Welfare to come up with a tight and effective selection criteria to ensure that the most deserving children benefit from the programme.

\subsubsection{Inconsistence of government policies}

The general lack of synchronization of government policies in Zimbabwe dealt a blow to the achievements of BEAM. For instance, the apparent weak link between BEAM and Operation Restore Order in particular, needs serious consideration by policy makers for the programme to be more effective. Operation Restore Order was a government programme meant to restore town planning by doing away with illegal structures. The operation created a set of new problems in its aftermath which included increasing the number of school dropouts as people were displaced and others lost their sources of livelihoods in the process and thus failed to keep their children in school. For effective poverty alleviation, there is need for a strong link between the government's poverty alleviation strategies and other macro-economic policies.

\section{Conclusion}

The study sought to determine the future and prospects of BEAM as a participatory strategy to poverty alleviation through government education assistance in Zimbabwe. Indications were that BEAM has been plagued with challenges since its inception which included inadequacy as well as late disbursement of funds. To ensure that BEAM as a participatory approach towards poverty alleviation plays an effective role in reducing the number of school dropouts, there is need for collaborative effort from all stakeholders with the Government playing a larger role.

\section{References}

Books

Anderson J, Public Policy Making. New York: Winston, 1984.

Chisvo, M. A Review of the Social Dimension of Adjustment in Zimbabwe 1990-1994, UNICEF, Harare: 1994.

Dye, T. Understanding Public Policy. New Jersey: Prentice Hall, 1984.

Edwards, G. E. Implementing Public Policy. Washington D. C. Congressional Quarterly Printers, 1980.

Howlett, M. and Ramesh, M. Studying Public Policy. Toronto: Oxford University Press,1995. 
Jenkins C. Economic Policy Investment in Zimbabwe 1980-1989. Centre for the Study of African Economics. University of Oxford, 1995.

Jenkins, C. and Prinsloo, E. Inequality among Households in Zimbabwe: An Assessment Using the 1990/91 ICES. Centre for the Study of African Economies Oxford University, 1993.

Klugman, J. and Helmsing. A. H. Decentralisation in Zimbabwe Human Development,1995.

Korteen, D. C. Rudi, K (eds) People-Centred Development: Contributions Toward Theory and Planning Framework. Connecticut: Kumanan Press, 1984.

Lindblom, C. The Policy Making Process. New Jersey: Prentice-Hall, 1980.

Lisk, F. (ed) Popular Participation in Planning for Basic Needs. Longmead: BlackmorePress, 1985.

Loeweson, R. The Social Dimension of Structural Adjustment. Harare: ZIDS, 1991.

Makumbe, J. M. W. Participatory Development, Harare: University of Zimbabwe Publications, 1992.

Mlambo, A. S. The Economic Structural Adjustment Programme. The case of Zimbabwe, 1990-1995. Harare: UZ Publications, 1997.

Mwanza, A. (ed)_Social Policy in an Economy under stress: The case of Zimbabwe Harare: SAPES Books, 1999.

Narayan, D. (ed) Empowerment and Poverty Reduction. A Source Book. The World Bank, New York, 2002.

Powell, F. "Training for Participation," in Institute of Cultural Affairs International, Brussels, (ed). Approaches that Work in Rural Development. New York: K. G. Saur, 1988.

Sabbatier, P. A. "Top-down Bottom-up Approaches in Implementation Research" in Michael, C (ed) The Policy Process. A Reader. Harvester Wheatsheaf, 1995.

Sachikonye L. "The State and the Union Movement in Zimbabwe. Cooptation, Conflict and Accommodation." (Unpublished mimeo 1997).

Shadur M. Labour Relations in a Developing Country: A Case study in Zimbabwe. Averbry, 1994.

Reports

CSO Consumer Price Index January 2006.

Constitution of Zimbabwe Amendment No. 17

Government of Zimbabwe Socio-economic Review 1980-1985. Harare: Government Printers. Government of Zimbabwe Poverty Alleviation Action Plan, 1994. 


\section{Macrothink \\ Journal of Public Administration and Governance ISSN 2161-7104 2015, Vol. 5, No. 3}

Government of Zimbabwe Poverty Assessment Study Report, 1997.

MPSLSW BEAM Status Report 2005.

Poverty in Zimbabwe. CSO, 1998.

United Nations Economic Commission for Africa Report. "Decentralisation Practices and Trends in Africa." Addis Ababa: 1989.

UN Report on Operation Restore Order, August 2005.

United Nations, Popular Participation in Decision Making for Development. (UN

Department of Economics and Social Affairs, New York, 1975).

UNDP Poverty Report, 2000.

UNDP Poverty Report, 2005.

World Bank Human Development Report, 1998, Zimbabwe.

World Bank Human Development Report 1994.

World Bank Social Protection Strategy paper, 1999.

World Bank Development Indicators, 2000.

World Bank Human Development Report 2003, Zimbabwe. 